\title{
Effect of Machined Surface Integrity on Fatigue Performance of Metal Workpiece: A Review
}

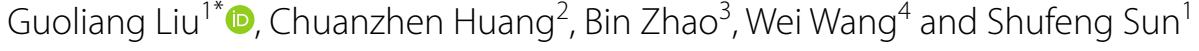

\begin{abstract}
Fatigue performance is a serious concern for mechanical components subject to cyclical stresses, particularly where safety is paramount. The fatigue performance of components relies closely on their surface integrity because the fatigue cracks generally initiate from free surfaces. This paper reviewed the published data, which addressed the effects of machined surface integrity on the fatigue performance of metal workpieces. Limitations in existing studies and the future directions in anti-fatigue manufacturing field were proposed. The remarkable surface topography (e.g., low roughness and few local defects and inclusions) and large compressive residual stress are beneficial to fatigue performance. However, the indicators that describe the effects of surface topography and residual stress accurately need further study and exploration. The effect of residual stress relaxation under cycle loadings needs to be precisely modeled precisely. The effect of work hardening on fatigue performance had two aspects. Work hardening could increase the material yield strength, thereby delaying crack nucleation. However, increased brittleness could accelerate crack propagation. Thus, finding the effective control mechanism and method of work hardening is urgently needed to enhance the fatigue performance of machined components. The machining-induced metallurgical structure changes, such as white layer, grain refinement, dislocation, and martensitic transformation affect the fatigue performance of a workpiece significantly. However, the unified and exact conclusion needs to be investigated deeply. Finally, different surface integrity factors had complicated reciprocal effects on fatigue performance. As such, studying the comprehensive influence of surface integrity further and establishing the reliable prediction model of workpiece fatigue performance are meaningful for improving reliability of components and reducing test cost.
\end{abstract}

Keywords: Surface integrity, Machining, Fatigue performance, Reciprocal effects

\section{Introduction}

The requirements of high reliability and long service life are increasingly stringent for mechanical components used in aerospace field. Fatigue fracture is a main failure mode of mechanical components subjected to cyclical mechanical and thermal loads, and fatigue failure is generally sudden and can lead to disastrous results. According to the statistics of Cowles B in 1996 (Figure 1),

\footnotetext{
*Correspondence: liuguoliang@qut.edu.cn

${ }^{1}$ School of Mechanical \& Automotive Engineering, Qingdao University

of Technology, Qingdao 266033, China

Full list of author information is available at the end of the article
}

fatigue-related failures account for $49 \%$ of all typical component failure modes in military gas turbine engines [1]. Therefore, fatigue performance is critical for the mechanical components subjected to cyclical stresses. Experiments prove that fatigue cracks are usually initiated from free surfaces. Thus, fatigue performance was highly dependent on the integrity of machined surface [2-4]. Consequently, great efforts have been exerted by researchers to improve the fatigue performance of machined components by enhancing their surface integrity, such as by optimizing machining parameters and developing new inserts [5]. The fatigue strength of surfaces obtained by different kinds of machining processes 


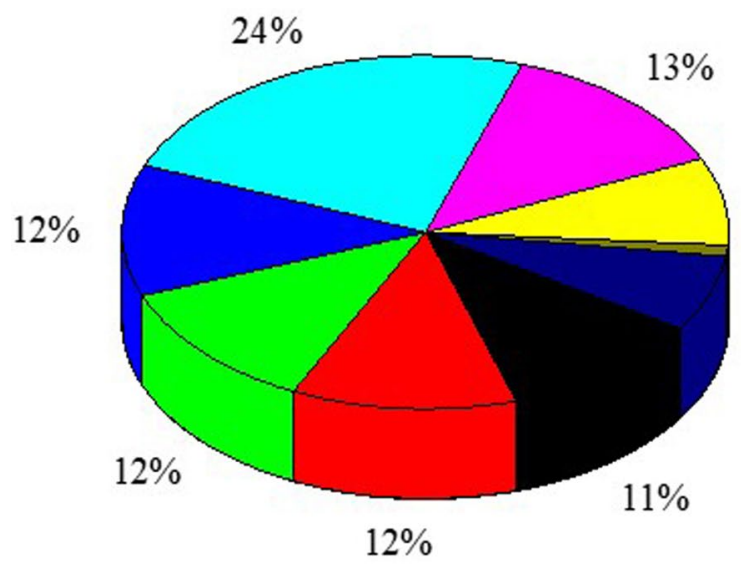

$8 \%$

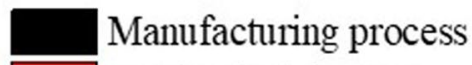

Mechanical damage

Overstress

Low cycle fatigue

High cycle fatigue

$1 \%$

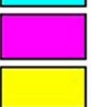

All other fatigue

$7 \%$

Corrosion

Thermal

$12 \%$

Figure 1 Representative jet engine component distress mode statistics [1]

has been compared to assist in the selection of processing technology (Table 1) [6-20]. In addition, the effects of machining parameters of certain machining technology, such as cutting speed [3, 21-24], feed rate [4, 22, 25-27], tool rake angle [28], and tool wear [29], were investigated. In most studies about the fatigue performance of machined components, the machined surface integrity, including the surface topography (e.g., surface roughness, local defects and inclusions) [30-33], residual stress [28, 34, 35], work hardening [36-39], and metallurgical structure changing [40-42], was considered as the bridge to reveal the internal mechanism of changed fatigue performance of a workpiece. However, disagreements are still observed in these studies because the tested workpiece materials, which covered steel [6-10], stainless steel [18], titanium alloy [15, 17, 20], Ni-base superalloy [13], and aluminum alloy [19], fatigue performance testing methods, and loading magnitudes vary (Table 1 ).

To express the research status and guide future research work in improving the fatigue performance of machined metal components, this paper will summarize the published data that addressed the effects of machined

Table 1 Effect comparison of machining technology on the fatigue performance

\begin{tabular}{lllll}
\hline Processes & Material & Fatigue testing method & Better process & Paramount surface integrity \\
\hline Turning vs. grinding & AISI 52100 steel [6] & Axial & Turning & Residual stress \\
& AISI 52100 steel [7] & Rolling contact & Turning & Not clear \\
& AISI 52100 steel [8,9] & Rolling contact & Turning & Residual stress \\
& JIS SUJ2 steel [10] & Axial & Turning & Surface roughness, work \\
& & & hardening \\
Turning vs. ECM & Y-titanium aluminide alloy [11] & Not clear & Turning & Residual stress \\
Milling vs. grinding & Y-titanium aluminide alloy [12] & Four-point bending & Milling & Residual stress \\
& Ni-base alloy [13] & Axial & Milling & Surface roughness \\
Milling vs. grinding, polishing & En19 steel [14] & Three-point bending & Polishing & Surface roughness \\
& Titanium alloy [15] & Four-point bending & Not clear & Non-uniformly distributed \\
& SAE J438b steel [16] & Three-point bending & Milling & Residual stress, phase transform \\
Milling vs. EDM & Titanium alloy [17] & Axial & Milling & Surface roughness, recast layer \\
& AlSI 304 stainless steel [18] & Four-point bending & EDM & Not clear \\
EP vs. SP, RB and DR & Titanium, aluminum, magne- & Axial and rotating bending & Depend on the material &
\end{tabular}

Note: ECM means electro-chemical machining, EDM means electro-discharge machining, EP means electrolytical polishing, SP means shot-peening, RB means rollerburnishing, DR means deep-rolling, LBM means laser-beam machining and AWJM means abrasive water-jet machining. 
surface integrity on the fatigue performance of metallic materials. The effects of surface topography, residual stress, work hardening, and metallurgical structure changes will be detailed individually, and their reciprocal effects will be discussed. The limitations in existing studies and the future directions in anti-fatigue manufacturing field will be summarized.

\section{Effect of Surface Topography on Fatigue Performance}

The effects of surface topography, including the surface roughness, local defects and inclusions, on workpiece fatigue performance have been studied in the early 1930s [4], and several agreements have been reached to data.

First, the surface roughness, local defects, and inclusions on the machined surface could affect the fatigue performance of a workpiece [16, 30-33, 43, 44]. The large surface roughness, local defects, and inclusions could degrade the fatigue performance of a workpiece [21, 34, $45-48]$.

Second, the surface topography mainly affects crack initiation and has no obvious effect on crack propagation [49-51]. Therefore, most studies stated that surface topography was mainly related to the high-cycle fatigue performance because the high-cycle fatigue performance mainly depended on the crack initiation stage, and the crack propagation life accounts for the main part of the low-cycle fatigue performance $[16,52,53]$.

Finally, the influence degree of surface topography was determined by workpiece material properties [54-56], workpiece geometry [51], and loading stress magnitude
[24, 57]. Figure 2 summarized the fatigue limits of several materials (e.g., iron, Ni-based alloy and titanium alloy) under different surface roughness generated by varying machining conditions [54]. Under gentle machining conditions, the endurance limit of AISI 4340 steel changed significantly with various surface roughness, whereas the endurance limit of Inconel 718 was not dependent on surface roughness.

\subsection{Effect of Surface Roughness on Fatigue Performance}

In earlier studies, the arithmetic average height of the surface profile, $R a$, was generally considered the only factor that affected the fatigue performance of machined workpieces [58, 59]. As research progresses, increasing researchers emphasized that $R a$ cannot characterize all surface topography features that were important to the fatigue performance [60]. In subsequent studies, the surface profile height parameters, such as $R z$ (maximum height of profile), $R z^{\prime \prime}$ (maximum height of stochastic surface roughness curve), and $R t$ (total height of profile) [13, 14, 61]; The hybrid parameters, such as $\Delta q$ (root mean square slope) and $\lambda q$ (spacing between local peaks and valleys) [61]; the 3D surface topography parameters, such as $\mathrm{Sa}$ (arithmetic mean surface height), Std (texture direction) and $\mathrm{Sal}$ (the fastest decay autocorrelation length); and the volume parameters, such as $S c i$ (core fluid retention index), Svi (valley fluid retention index), and Ssc (arithmetic mean summit curvature of the surface) $[62,63]$, were relevant to fatigue strength.

However, the most effective indicator was controversial (Table 2). Bayoumi et al. [61] investigated the

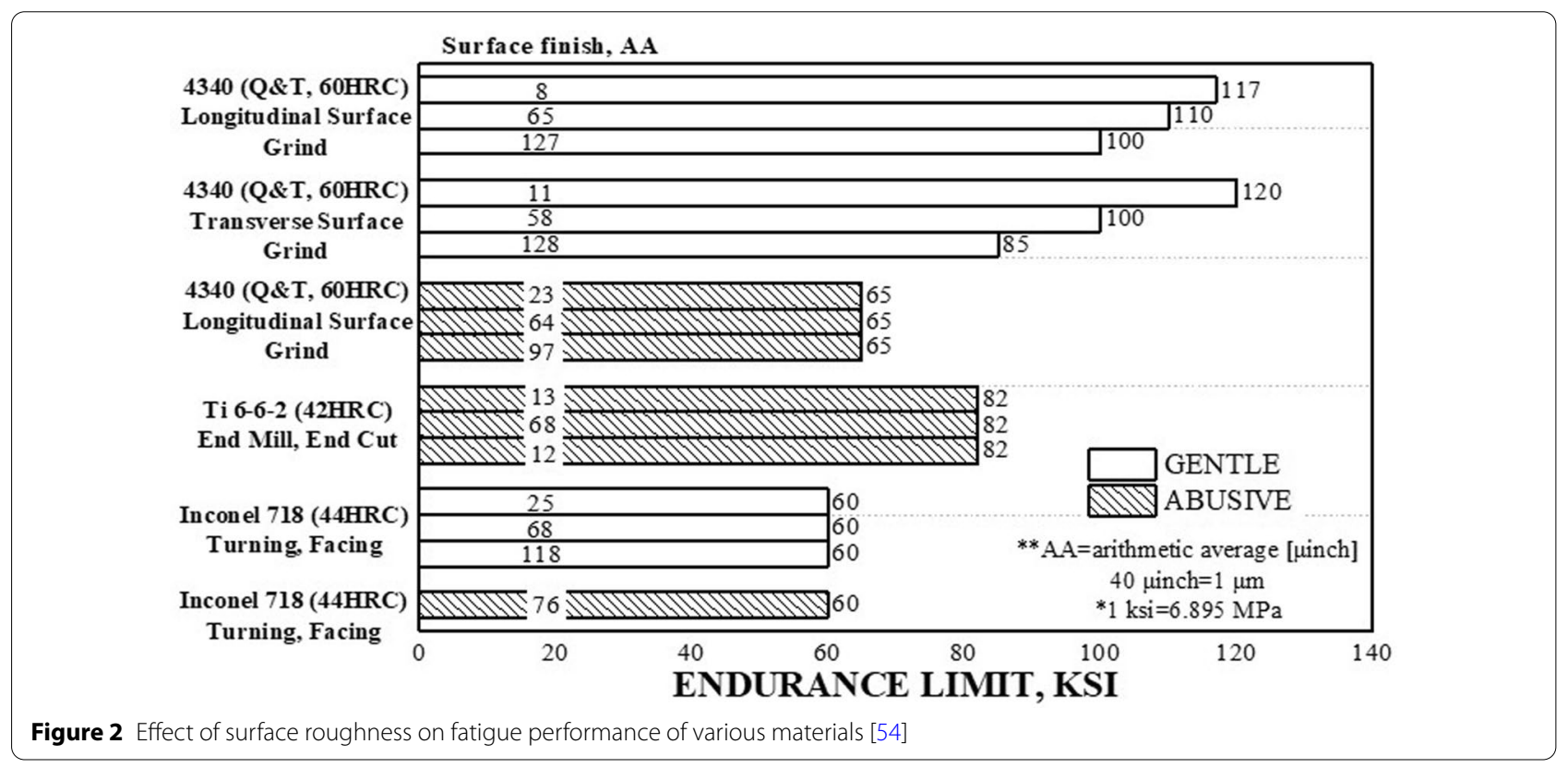


Table 2 Most effective indicator of surface roughness on workpiece fatigue life

\begin{tabular}{llll}
\hline Researcher & Material & Fatigue testing method & Most effective indicator \\
\hline Bayoumi et al. [61] & Aluminum alloy & Rotating bending & Amplitude parameters $(R a$ and $R q)$ \\
Taylor et al. [14] & Steels and non-ferrous alloys & Three-point bending & Height parameters $(R z$ and $R t)$ \\
Siebel [64] & Steels & Axial & Height parameters $(R t)$ \\
Yang et al. [21] & Titanium Alloy & Axial & Three-dimensional parameters \\
Abroug et al. [62] & AA7050 alloy & Plane bending & Sa \\
\hline
\end{tabular}

correlation between the surface roughness parameters and the rotating bending fatigue endurance limit of an aluminum alloy and found that the amplitude parameters (e.g., $R a$ and $R q$ (root mean square height of the surface profile)) were more important in affecting fatigue endurance limit than the height (e.g., $R z$ and $R t$ ) and hybrid parameters (e.g., $\Delta q$ and $\lambda q$ ). Nevertheless, Taylor et al. [14] stated that the effects of height parameters (e.g., $R z$ and $R t$ ) on the fatigue performance were the most significant among all the roughness parameters after testing the fatigue performance of various steels and non-ferrous alloys. Siebel [64] also believed that the effect of height parameters was crucial because they found that when the groove depth exceeded the critical value $(R o)$, the reduction in fatigue endurance limit was proportional to $\log R t$ (Figure 3 ). In addition, Yang et al. [21] suggested that the fatigue life models based on surface stress concentration factor that was calculated by using three-dimensional surface roughness parameters were more accurate than that using two-dimensional ones. Abroug et al. [62] stated that the 3D amplitude parameters $S a$ characterized the fatigue behavior of milled surfaces the best.

Griffiths [63] also summarized the influence degree of different surface roughness parameters on the fatigue performance of workpieces by conducting a comprehensive survey over the existing studies, and the results are shown in Table 3.

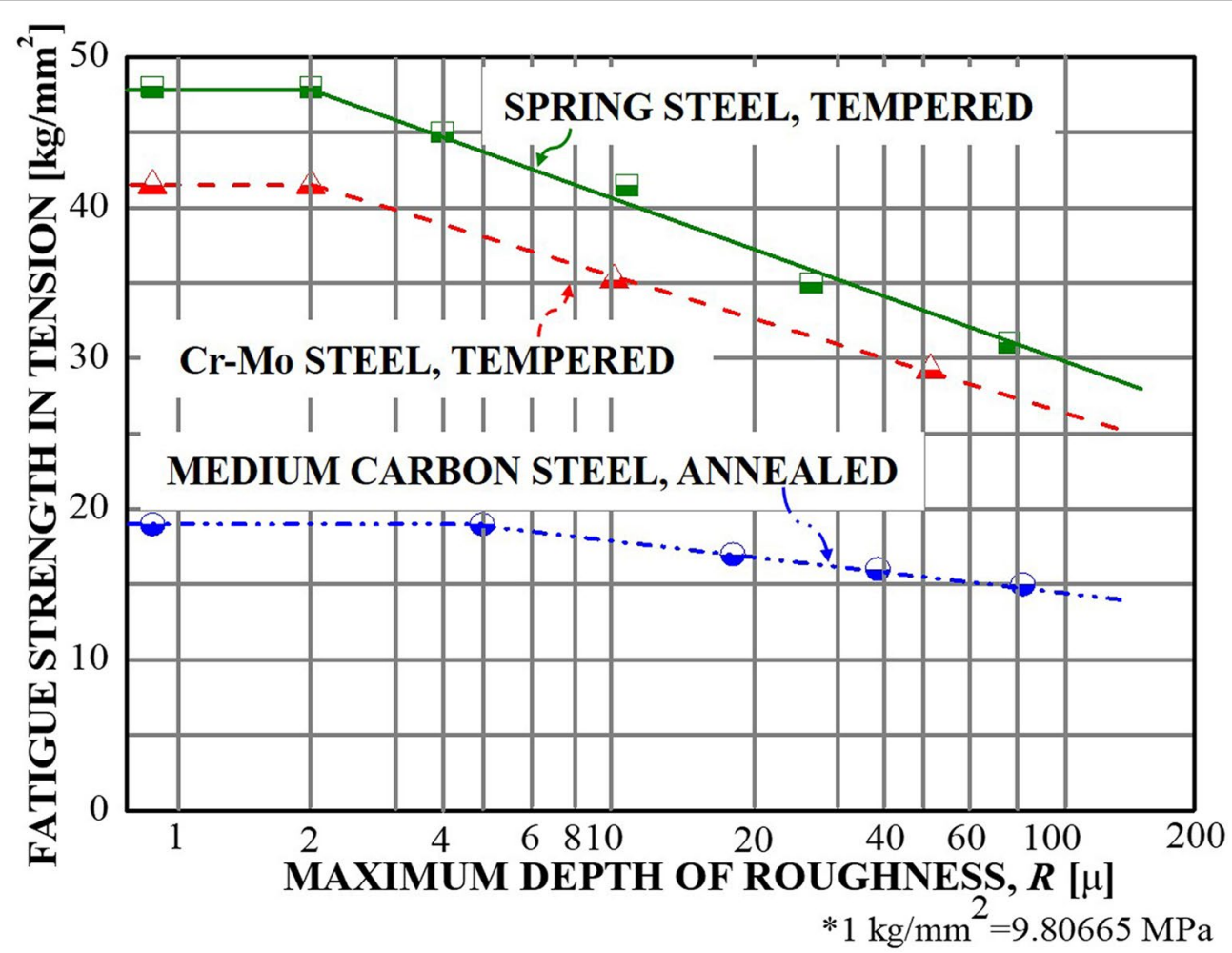

Figure 3 Fatigue strength in tension of various steels as a function of surface roughness [64] 
Table 3 Influence degree of surface roughness parameters on workpiece fatigue life [63]

\begin{tabular}{ll}
\hline Parameter & Effect \\
\hline Heights $R a, R q, R t$, Sa, Sq & Much \\
Distribution and shape Rsk, Rku, Ssk, Sku & Some \\
Slopes and curvature $R \triangle q, S \triangle a$ & Little \\
Lengths and peak space Rsm, HSC & Little \\
Lay and lead Std, Sal & Much \\
\hline
\end{tabular}

\subsection{Effect of Other Topography Parameters on Fatigue Performance}

Aside from the surface roughness, the sharpness of profile [31, 65], the size and shape of local defects [33, $66,67]$, the shape and direction of machining marks $[14,35]$, the size and location of inclusions $[32,43]$ and the size of microcracks $[11,68,69]$ were also proven to be influential on fatigue performance. Leverant et al. [65] proposed that the sharpness (e.g., profile valley radius) of machining grooves was more critical than the maximum height of the profile $(R z)$ when studying the fatigue properties of Ti-6A1-4V titanium alloy. Warhadpande and Sadeghi [31] confirmed the important effects of surface dent sharpness on the rolling contact fatigue life. Taraf et al. [33] investigated the effects of size and shape of surface defects on the railway wheel fatigue damage and found that the fatigue life of workpieces with circular defects was longer than those with elliptical defects. The increased size of defects could degrade fatigue performance substantially. Several studies [11, $68,69]$ revealed that the machining-induced microcracks may propagate directly to cause fatigue failure, although some disagreements about the critical value of microcracks in these studies were addressed.

Güngör and Edwards [32] compared the effect degree of inclusions and surface roughness on the fatigue performance of forged 6082 aluminum alloy and found that the inclusions with a diameter of $20-80 \mu \mathrm{m}$ at the specimen surface could act as crack nucleation sites. Deng et al. [70] also found the fatigue cracks that initiated from the inclusions when the fatigue fracture surfaces of carburized $12 \mathrm{Cr} 2 \mathrm{Ni}$ were observed (Figure 4). These results agreed well with some other researchers who suggested that if the size of the surface inclusions was an order of magnitude higher than the $R a$ value, then they could outweigh any effect on fatigue performance because of surface roughness [4, 15]. Hereby, Saberifar et al. [43] stated that for a given stress, the critical inclusion size for crack nucleation could be increased by eliminating the surface roughness.

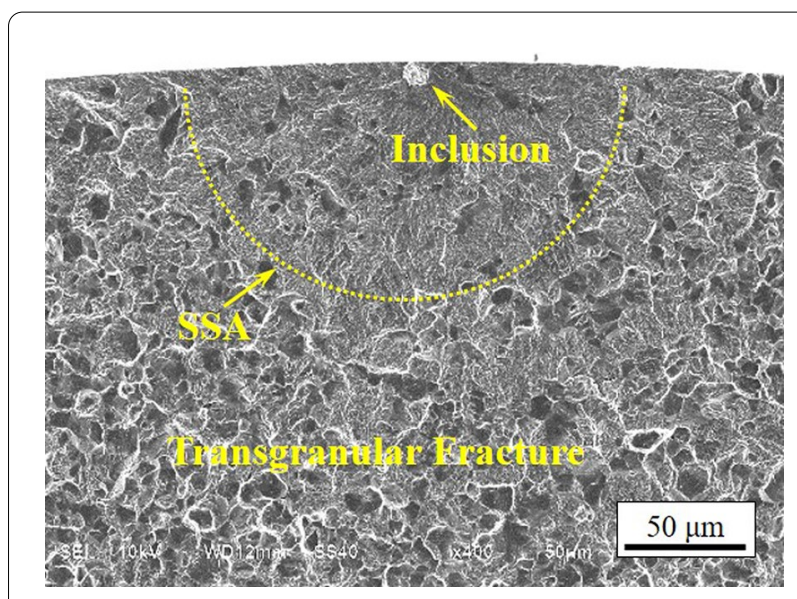

Figure 4 Fracture surface of a fatigue crack which initiated from an inclusion [70]

\subsection{Limitation}

The main limitation that exists in the aforementioned studies is that the effects of surface topography on fatigue performance have not been described well using appropriate indicators or methods.

Given that the surface topography mainly affects the material fatigue performance by resulting in stress concentration, the stress concentration factor $\left(K_{t}\right)$ was adopted by many researchers as the aggregative indicator to represent the comprehensive influence of surface topography [71]. Several models and methods were presented to calculate the $K_{t}$. Based on the equation of $K_{t}$ for a single surface notch in a panel subjected to uniform tension (i.e., Eq. (1)), Neuber [72] proposed the semiempirical equation of $K_{t}$ using standard roughness parameters (Eq. (2)):

$$
K_{t}=1+2 \sqrt{\frac{t}{\rho}},
$$

where $t$ is the notch height and $\rho$ is the notch root radius.

$$
K_{t}=1+n \sqrt{\lambda \frac{R_{z}}{\rho}},
$$

where $n$ represents the stress state $(n=1$ for shear and $n=2$ for tension). $R z$ and $\rho$ are the 10-point surface height and notch root radius, respectively. $\lambda$ is the ratio between spacing $(b)$ and height $(t)$ of surface irregularities, $\lambda=b / t$ (Figure 5).

Arola et al. [73] developed a new model to calculate the effective stress concentration factor $\left(\overline{K_{t}}\right)$ of machined surface texture (Eq. (3)). The arithmetical average roughness $(R a)$, peak-to-valley height $(R y), 10$-point surface 

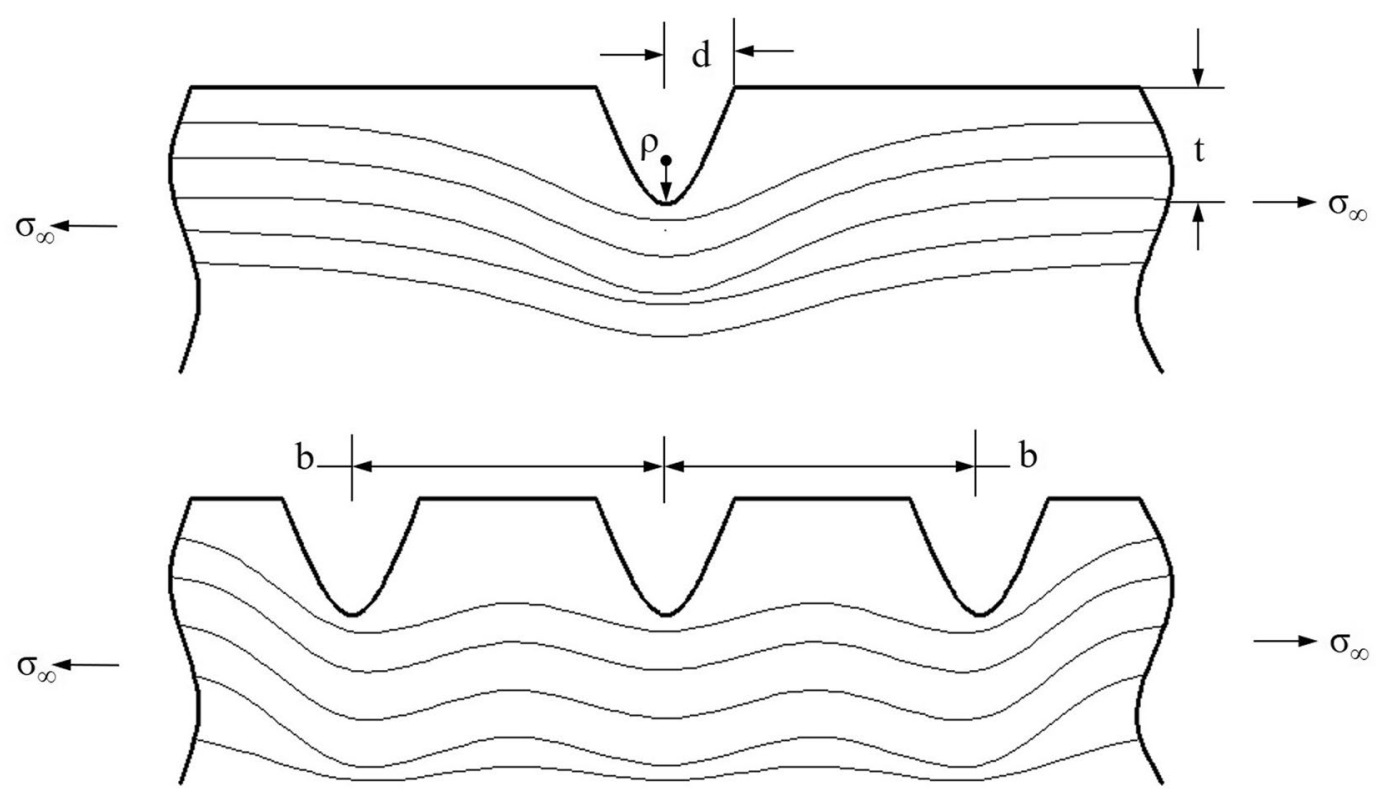

Figure 5 Near-notch stress trajectories for single and multiple surface notches [57]

height $(R z)$, and effective profile valley radius $(\bar{\rho})$ were considered.

$$
\overline{K_{t}}=1+n\left(\frac{R_{a}}{\bar{\rho}}\right)\left(\frac{R_{y}}{R_{z}}\right),
$$

where $n$ is the empirical constant that represents the stress state as well ( $n=1$ for shear and $n=2$ for tension).

Except for the aforementioned mathematical model, the finite element (FE) analysis was also adopted to obtain the machined surface stress condition $[44,60,71$, $74]$. The sample surface profile was measured and used to generate the FE model. Uniform tensile load was applied after defining the material properties and meshing. The maximal and normal von Mises equivalent stresses were extracted, and the stress concentration factor $\left(K_{t}\right)$ was determined by using Eq. (4).

$$
K_{t}=\frac{\sigma_{\max }}{\sigma_{\text {nom }}}
$$

where $\sigma_{\text {max }}$ and $\sigma_{\text {nom }}$ are the maximal and normal von Mises equivalent stress, respectively. The principle of getting $\sigma_{\max }$ and $\sigma_{\text {nom }}$ by finite element calculation is shown in Figure 6.

However, although the stress concentration factor $\left(K_{t}\right)$ was a useful indicator to reveal the effect mechanism of surface topography on fatigue performance to some extent, it still has some defects.

First, the stress concentration factor could not effectively describe the effects of microcracks that can

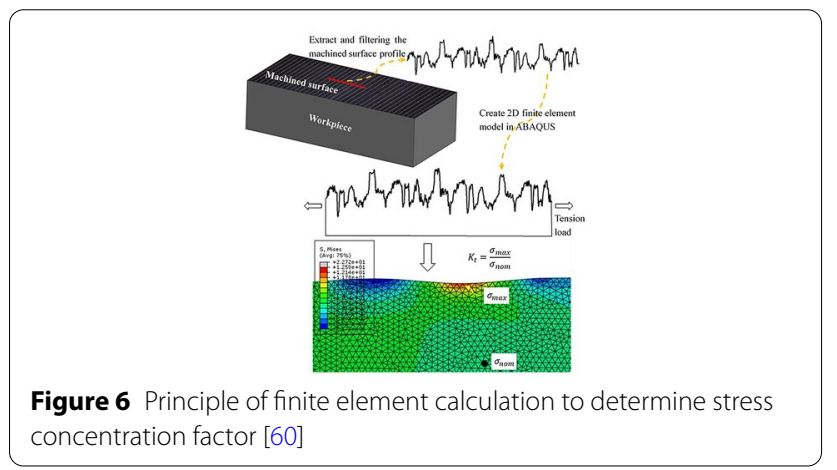

propagate directly to cause fatigue failure. In addition, the stress concentration factor did not consider the material properties, the shape and direction of machining marks, and the critical value of surface roughness, defects, and inclusions. The effect degrees of surface topography on fatigue performance differed for various workpiece material properties [54], and machining defect shapes [14, 35]. Finally, the stress concentration factor $\left(K_{t}\right)$ attributed the effects of surface topography to the notch effect wholly. However, some researchers found that the true effect of surface topography on fatigue performance was not as notable as that of the stress concentration factor [75, 76]. Taylor and Clancy [14] proposed that the fracture mechanics approach led to better results than the notch effect mechanism for low roughness surfaces, in comparing the fatigue life of En19 steel machined by polishing, grinding, milling and shaping. 
Therefore, a more effective indicator that can fully characterize the influence of surface topography on machined workpiece fatigue performance needs to be explored further.

\section{Effect of Residual Stress on Fatigue Performance}

With the deep research in machined surface fatigue performance, many researchers suggested that the residual stress was also an important factor that affected the workpiece fatigue property aside from surface topography $[10,20,28,34]$. For the effects of residual stress on fatigue performance, the researchers had reached an agreement that the compressive residual stress can improve fatigue limit and the tensile residual stress can reduce fatigue resistance $[15,16,30,35,77-79]$. In the literature, tensile residual stress was identified as a significant factor that resulted in the poor fatigue performance of electro-discharged and laser-beam machined surfaces $[17,30,80]$. On the contrary, the compressive residual stress was widely used to explain the improved fatigue limit of surfaces produced by shot peening [81-85], turning $[6,11,26]$, milling $[12,76,86]$, and abrasive waterjet machining [20,30]. Smith et al. [6] and Koster [54] even considered that the effects of residual stress on fatigue performance were more significant than those of surface topography. El-Helieby and Rowe [87] also found that the relationship between the surface residual stress and the fatigue strength of ground En31 steel was approximately linear.

\subsection{Influence Mechanism and Critical Indicators of Residual Stress}

Although the influence mechanism of machined surface residual stress on fatigue performance has been widely investigated, it is still controversial. Most researchers agreed with the conclusion of Wagner and Gregory [49] that compressive residual stress could retard crack growth significantly, but its effect on crack initiation was insignificant. Some researchers $[11,88,89]$ believed that compressive residual stress could reduce the fatigue crack growth rate and thus improve the workpiece fatigue performance. Guo and Warren [8] suggested that the compressive residual stress could impede crack growth by closing the crack tip. However, some researchers compared the location of crack initiation of samples and found that the compressive residual stress could affect the fatigue crack initiation as well. Compressive residual stress could force the movement of the location of fatigue crack initiation from the sample surface to the subsurface $[75,84,90,91]$.

The disagreement on the influence mechanism of residual stress resulted in the argument on the most critical indicators of residual stress that determined the fatigue performance. The typical residual stress depth profile on the machined surfaces is as shown in Figure 7 (Obtained with hard turned bearing steel). Regardless whether the residual stress was tensile or compressive on the surface, it fell off to a maximum compressive state with an increase in depth. Subsequently, the compressive residual stress decreased gradually until a steady value was achieved in the near workpiece substrate [92-94].

Given that residual stress mainly affects crack growth but has no obvious effect on crack initiation, Koster [54] suggested that the subsurface residual stress controlled the workpiece fatigue behavior rather than the outer surface stress. However, Hua et al. [94] found that the surface principal residual stress could result in crack closure during cyclic loading and decreased crack propagation rate. Schwach et al. [95] stated that the surface residual stress value and the near-surface residual stress profile were significant for rolling contact fatigue. However, the depth of the maximum compressive residual stress in the subsurface was not crucial. Conversely, Drechsler et al. [96] and Hassan et al. [97] both suggested the importance of magnitude and influence depth of compressive residual stresses for the fatigue performance of a rotating beam. This result was supported by Wagner [19] and Klotz et al. [82], who found that high-cycle fatigue cracks nucleated at the position with the maximum tensile residual stress below the machined surface (Figure 8 (Obtain with shot peened Inconel 718)).

\subsection{Residual Stress Relaxation}

Although residual stress relaxation has been recognized to be non-negligible in analyzing the effect of residual stress on fatigue performance of workpiece, its effect degree was controversial [34, 81, 83]. Benedetti et al. [98] studied the reverse bending fatigue behavior of a shot peened 7075-T651 aluminum alloy and found that residual stress relaxation only existed when the material plastic flow stress was achieved in the compressive part of the loading cycle. This result agreed well with Hempel et al. [99] and Liu et al. [100], who all suggested that once the summation of residual stress and applied stress reached or exceeded the yield strength of workpiece material, the residual stress could mostly be released in several cycles, thereby resulting in the negligible effect of residual stress on fatigue performance. Based on this important finding, most researchers suggested that machined surface residual stress mainly affected the high-cycle fatigue (lowstress fatigue) $[16,101]$.

However, Ozdemir et al. [102] and Dalaei et al. [103] found that the relaxation of compressive residual stress could also occur under cyclic loadings even when the total loading is below the yield strength of the material. Zhuang et al. [104] and Torres et al. [105] suggested that 
residual stress relaxation was related to the applied stress value and the number of fatigue cycles, and an analytical model was proposed to estimate the residual stress relaxation (Eq. (5)):

$$
\frac{\sigma_{N}^{r e}}{\left|\sigma_{0}^{r e}\right|}=A\left(\frac{2 \sigma_{a}^{2}}{(1-R)\left(C_{w} \sigma_{y}\right)^{2}}\right)^{m}(N-1)^{B}-1,
$$

where $\left|\sigma_{0}^{r e}\right|$ and $\sigma_{N}^{r e}$ are the initial surface residual stress and the surface residual stress after $N$ cycles, respectively. $A$ and $m$ are material constants which dependent on cyclic stress and strain response. Constant $B$ controls the relaxation rate versus loading cycles. $\sigma_{a}$ is the cyclic load amplitude and $\sigma_{y}$ is the material yield strength. $C_{w}$ is a parameter which accounts for the degree of cold working. $R$ is the loading ratio and $N$ is the loading cycle.

Given the residual stress relaxation, Cretu and Popinceanu [106] suggested the existence of an optimum residual stress distribution that can achieve the best fatigue performance for a certain loading. However, the authors did not present the method for determining the optimum residual stress distribution.

\section{Effect of Work Hardening on Fatigue Performance}

In the machining processes, severe material plastic deformation could induce microstructure changes, including the storage of dislocations, grain refinement, and even phase transformation, thereby increasing the hardness of machined surface, also known as work hardening $[107,108]$. Work hardening was closely associated with material fatigue performance $[2,8,23]$. According to the existing literature, the effect of work hardening on workpiece fatigue performance was an extremely controversial subject.
Jones et al. [109] explored the effects of strain hardening on the load bearing capacity of a rail steel and found that the material yield strength was proportional to its Vickers hardness (Eq. (6)):

$$
k=\frac{\sigma_{y}}{\sqrt{3}}=\frac{H_{V}}{3 \sqrt{3}}
$$

where $k$ is the shear yield strength, $\sigma_{y}$ is the yield strength and $H_{V}$ is the Vickers hardness.

Choi [25] established a crack propagation life model to describe the fatigue performance of turned AISI 1053 steel by considering its material properties (Eq. (7)). The model shows that high surface hardness could result in long crack propagation life.

$$
N_{P}=\int_{a_{1}}^{a_{2}} \frac{1}{C_{\frac{H_{b}}{H_{l}}(\Delta K)^{n}} \mathrm{~d} a}
$$

where $N_{P}$ is the crack propagation life. $a_{1}$ and $a_{2}$ are the half length of initial and final crack, respectively. $C$ is the material constant. $H_{b}$ is the Knoop hardness of the bulk material, and $H_{l}$ is the local Knoop hardness. $\Delta K$ is the stress intensity factor range at the leading tip. $n$ is the slope index.

Murakami [110] further suggested that the material fatigue strength was proportional to its Vickers hardness and could be expressed by using Eq. (8). This result was adopted and confirmed by many researchers. Sasahara [35] studied the effects of work hardening on the fatigue performance of machined steel and stated that work hardening could improve its yield strength, thereby prolonging fatigue life. Nishida et al. [111] also found that work hardening can improve the fatigue strength of rolled S25C steel. Similar results on various metallic materials, such as the Ni-based superalloy [13, 30, 52], steel [83, 112], and stainless steel [113], were also
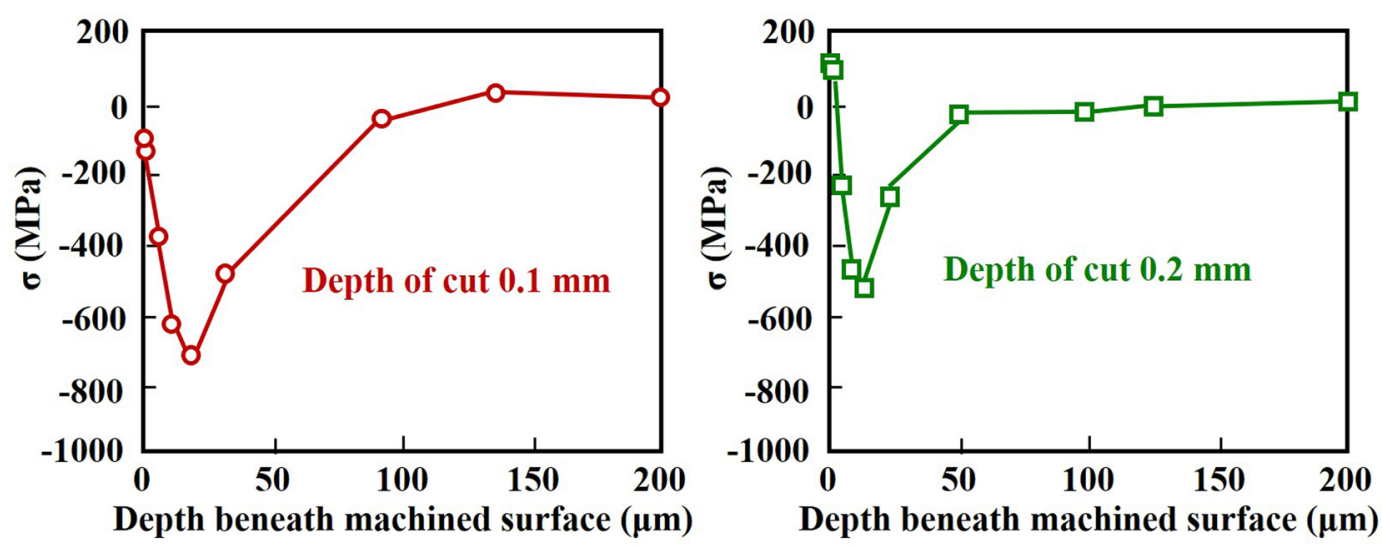

Figure 7 The typical residual stress depth profile with compressive (left) and tensile (right) surface residual stress [92] 
(a)

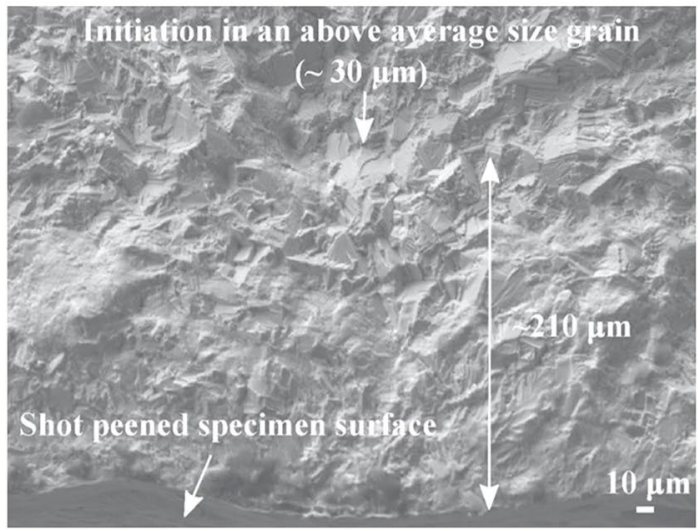

\section{(b) Tension}

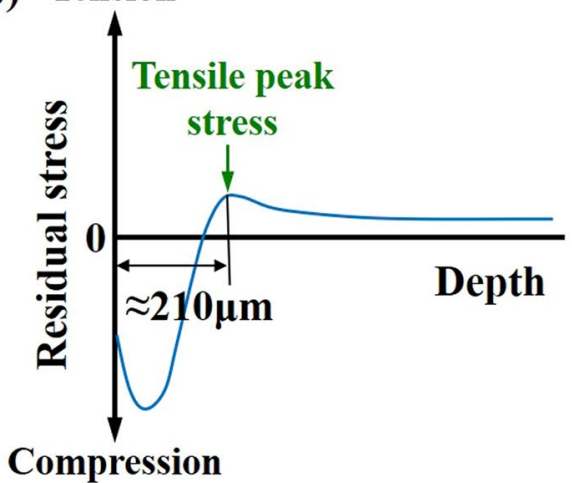

Figure 8 Crack initiation at the position with maximum tensile residual stress: a fractured surface and $\mathbf{b}$ residual stress depth profile [82]

obtained by researchers with different fatigue testing methods. Wagner [19] concluded that work hardening could inhibit fatigue crack initiation by increasing the yield strength, thereby improving the workpiece fatigue performance.

$$
\sigma_{M, w} \cong 1.6 H_{V},
$$

where $\sigma_{M, w}$ is the material fatigue strength and $H_{V}$ is the Vickers hardness.

Inés et al. [114] compared the rotating bending fatigue performance of original, gas-nitrided and shop peened $42 \mathrm{CrMo} 4$ steel and found that the effect of surface work hardening on fatigue crack propagation behavior was more significant than the residual stress field. On the contrary, although Iswanto et al. [115] confirmed that the bending fatigue limit of rolled stainless steel increased with work hardening, they suggested that the effect of compressive residual stress on the fatigue limit improvement of stainless steel was higher than that of work hardening. Martin et al. [39] studied the fatigue life of shot peened AA 6005-T6 aluminum alloy and stated that the effect degree of roughness, residual stress field, and work hardening on fatigue behavior depends on the material properties. For high-strength materials, roughness and residual stress field are expected to be more important in the fatigue behavior of the material than the increase in surface hardness. For materials with good work hardening capability and moderate mechanical strength, the increase in hardness was more relevant than the other variables.

Many researchers also suggested that work hardening could reduce the ductility and fracture toughness of machined surface, thereby reducing the inhibition of fatigue crack propagation (Table 4) $[9,49,116]$. Klumpp et al. [36] tested the influence of work hardening on fatigue crack growth, effective threshold and crack opening behavior of Ni-based superalloy Inconel 718 . High fatigue crack growth rate, low effective thresholds, and reduced crack opening stress intensities were observed in work-hardened material. Huang et al. [23] found that an appropriate surface strain hardening could contribute to the improvement of fatigue resistance. However, excessive surface strain hardening could increase surface brittleness and thus destroy fatigue resistance.

In addition, Mantle and Aspinwall [68] stated that the reduced ductility of material induced by work hardening was a barrier of producing defect-free surfaces. Once the machined surfaces contain microcracks, their fatigue performance would mainly depend on the crack propagation process and thus be reduced by work hardening [76, 86].

Fukui et al. found another adverse impact of work hardening on fatigue performance by studying the rolling contact fatigue endurance of high manganese austenitic steel [113]. They found that the fatigue cracks could be propagated easily along the boundary of the work hardening zone and the normal zone. The run-out of machined surface fatigue strength could be increased by work hardening because of the inhomogeneity of work hardening [12].

These observations suggested that the effect of work hardening on workpiece fatigue performance was twofaced and depended on the induced yield strength and fracture toughness. Liu et al. [100] tested the surface yield strength and fracture toughness of face-milled 17-4PH stainless steel by using the continuous ball indentation technique. It was found that the effect of work hardening on the surface yield strength and fracture toughness depended on its generating mechanism. When work hardening mainly resulted from plastic strain hardening, material fracture toughness seriously decreased and 
balanced the positive effect of increased yield strength on fatigue performance. However, when work hardening was mainly generated by grain refinement, the surface yield strength and fracture toughness increased simultaneously and prolonged the fatigue life. This result agreed well with that of Libor et al. [38], who used severe shop peening to induce grain refinement and produce a nanostructured surface layer on $50 \mathrm{CrMo} 4$ steel, which improved the fatigue strength by $23 \%$ in the ultra-high cycle fatigue regime (up to $10^{9}$ cycles). They suggested that the nano-crystallized structure of the surface layer of material could increase the stress to be applied for crack initiation. Zhao et al. [117] ascribed the fine crystal strengthening effect to the grain orientation. They found that the elongated grains in nano-crystallized structure are basically parallel to the external load, that id, they were perpendicular to crack propagation surface. In this direction, the grain boundaries are adverse to the incubation of crack, and are less likely for fatigue crack to initiate from this layer. Some other studies $[47,79,83$, $118,119]$ also found that grain refinement could improve material yield strength and ductile fracture toughness by suppressing the formation of martensite cracks and cleavage fracture. However, they did not provide effective control methods of work hardening to enhance the fatigue performance of machined components.

\section{Effect of Metallurgical Structure Changes on Fatigue Performance}

Aside from the grain refinement and metallurgical structure-changing induced work hardening, the effects of some other machining-induced metallurgical structure changes on machined workpiece fatigue performance were also studied by researchers.

Nishida et al. [111] suggested that the deformed laminated structure of roller worked steel JIS S25C improved fatigue strength compared with the non-roller worked specimens with laminated parallel structures. They considered that the deformed structure can prevent crack initiation and resist the propagation of fatigue cracks into the interior region during fatigue tests. Rio et al. [41] also believed that the grain boundaries could act as barriers to plastic flow in the zone ahead of the crack tip. However,

Table 4 The effect of surface layer properties on crack nucleation and propagation [49]

\begin{tabular}{lll}
\hline & Crack nucleation & Crack propagation \\
\hline Surface roughness & Accelerates & No effect \\
Cold work & Retards & Accelerates \\
Residual compressive stress & Minor or no effect & Retards \\
\hline
\end{tabular}

Cox et al. [120] stated that the mismatched dislocations was harmful to the machined workpiece fatigue performance because the micro-cracks along unfavorably aligned basal planes in the alpha phase at the machined subsurface of metastable $\beta$ titanium alloy Ti-5553 was the dominant crack initiation mechanism.

The effects of martensitic transformation in the machined surface layer on the fatigue performance were investigated in several research. Chen et al. [121, 122] suggested that compared with the austenite structure, the transformed martensite tissue was harmful to the fatigue strength. The boundaries of martensite lath were conducive to crack propagation, which could reduce the workpiece fatigue performance. In addition, the austenite could sustain larger plastic deformation, and the martensitic transformation during fatigue process could absorb energy and relax the stress concentration at the crack tip, thereby hindering the propagation of fatigue cracks. However, Uematsu et al. [123] tested the rotating bending fatigue performance of cyclically pre-strained 304 austenitic stainless steel and found that the high-volume fraction and uniform distribution of martensitic phase induced the transition of crack initiation mechanism and increased fatigue limit. In addition, although the martensitic transformation reduced the fatigue strength of 304 stainless steel remarkably in $3 \% \mathrm{NaCl}$ solution at $-25^{\circ} \mathrm{C}$, Nakajima et al. [40] proved that the quantity of straininduced martensitic phase did not affect the fatigue strength of 304 stainless steel in laboratory air condition. Their experiments confirmed that the quantity of martensitic transformation hardly influenced the crack growth behavior because the strain-induced martensitic transformation occurred in the slip bands and fatigue crack initiated within the austenitic phase.

As the result of severe plastic deformation or resolidification of melted metal during thermal machining process, "white layer" is a kind of serious metallurgical structural changes. The effects of white layer on the workpiece fatigue performance were investigated specifically by some researchers. Although a few researchers $[6$, 124] suggested that the effect of white layer on high-cycle tension-tension fatigue performance was less significant than residual stress, most researchers believed that the white layer was severely detrimental to fatigue performance $[125,126]$. The dendritic structure with microcracks in the white layer, which typically runs normal to the machined surface (Figure 9), could work as the crack initiation source [16]. In addition, the high brittleness of the white layer was conducive to the crack initiation and propagation and thus could destroy the fatigue performance. Shur et al. [126] proved experimentally that cracks were easier to form in the white layer and propagate along the boundary between the white layer 
and the substrate under the compressing load and plastic deformation. Schwach et al. [95] and Guo et al. [125] also confirmed a negative effect of white layer on fatigue performance by comparing the rolling contact fatigue lives of the samples with and without white layer. Their results showed that fatigue life severely decreased with the increased thickness of white layer.

Although the effects of metallurgical structure changes on the machined workpiece fatigue performance have been studied by many researchers, unified and exact conclusions have not been reached. The effective workpiece fatigue performance prediction model (or method) based on the metallurgical structure changes has not been established.

\section{Reciprocal Effect of Different Factors on Fatigue Performance}

Although the effect of surface topography, residual stress, work hardening and metallurgical structure changes on machined workpiece fatigue performance was discussed separately above, the machining processes usually change these surface integrity factors synchronously $[3$, 82]. Given that all of these factors can change the fatigue crack initiation and propagation processes, reciprocal effects must exist among them. As such, the fatigue performance of the machined workpiece is determined by their comprehensive influence $[76,93]$. The reciprocal effects of different surface integrity factors on fatigue performance were analyzed and summarized in Figure 10.

First, based on the effects of poor surface topography and compressive residual stress on fatigue crack initiation and propagation process, concluding that their effects on fatigue performance inhibit each other is easy. The poor surface topography (i.e., the large surface roughness, local defects and inclusions) could induce stress concentration and accelerate fatigue crack initiation [21, 71]. Stress concentration can enlarge the local loading on the workpiece severely, which may cause the local stress to reach or even exceed the material yield strength. Once the summation of residual stress and applied stress reached or exceeded the material yield strength, serious residual stress relaxation would occur $[99,100]$. Therefore, the severe stress concentration induced by poor surface topography could dilute the effect of compressive residual stress on fatigue performance by inducing residual stress relaxation.

In addition, Yao et al. [127] found that the poor surface topography could cause early unstable fracture and reduce the area ratio of the fatigue propagation zone. Nevertheless, many researchers suggested that the compressive residual stress mainly inhibit the crack propagation process to improve fatigue strength $[8,11,49$, $88,89]$. Therefore, the reduced fatigue propagation zone

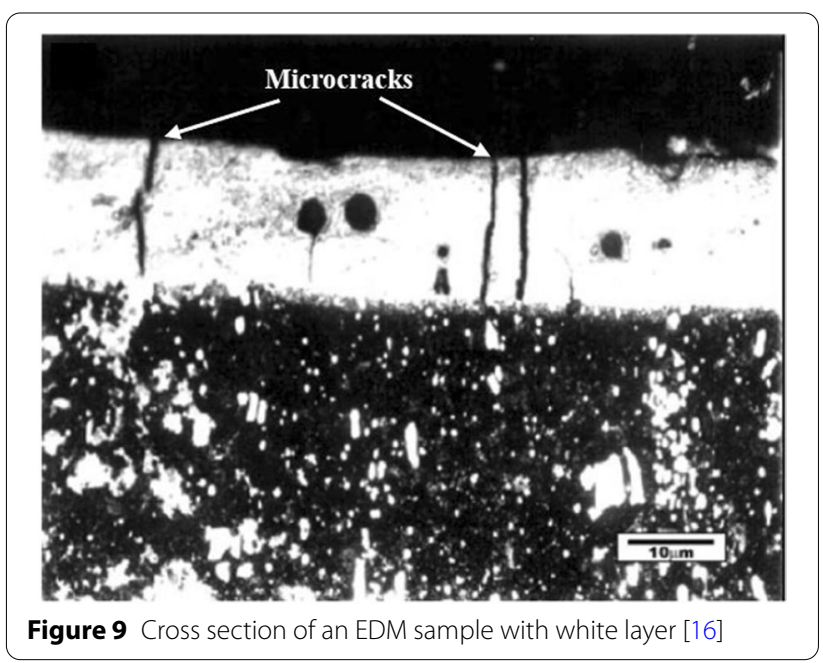

caused by poor surface topography could restrain the effect of compressive residual stress on inhibiting crack propagation and thus dilute the effect of compressive residual stress on fatigue performance.

In return, the crack tip closing [8] and the subsurface fatigue crack initiation $[75,84,90,91]$ induced by compressive residual stress could restrain the negative effect of poor surface topography on fatigue crack initiation.

Second, the reciprocal effect of poor surface topography and work hardening on fatigue performance was two-faced. On the one hand, based on the results above $[25,45,46,49]$, the poor surface topography mainly accelerates the fatigue crack nucleation, and the severe work hardening mainly accelerates the fatigue crack propagation. Therefore, their effects on fatigue performance can mutually combine to magnify each other. On the other hand, the increased yield strength induced by work hardening could inhibit the initiation of fatigue cracks [19,35], which runs counter to the effect of poor surface topography and thus restrain the effect of poor surface topography on fatigue performance.

Finally, the effect of work hardening and compressive residual stress on fatigue performance can interact with each other as well. The increased yield strength induced by work hardening can reduce the residual stress relaxation and thus reinforce the effect of compressive residual stress on fatigue performance. Sidhom et al. [37] demonstrated the interdependence between work hardening modification and residual stress redistribution under cyclic loading by experimental and numerical approaches, which suggested that the higher the near surface work hardening was, the more stable the initial residual stress will be. Nevertheless, the work-hardening induced high brittleness can accelerate the fatigue crack propagation [49], while the compressive residual 


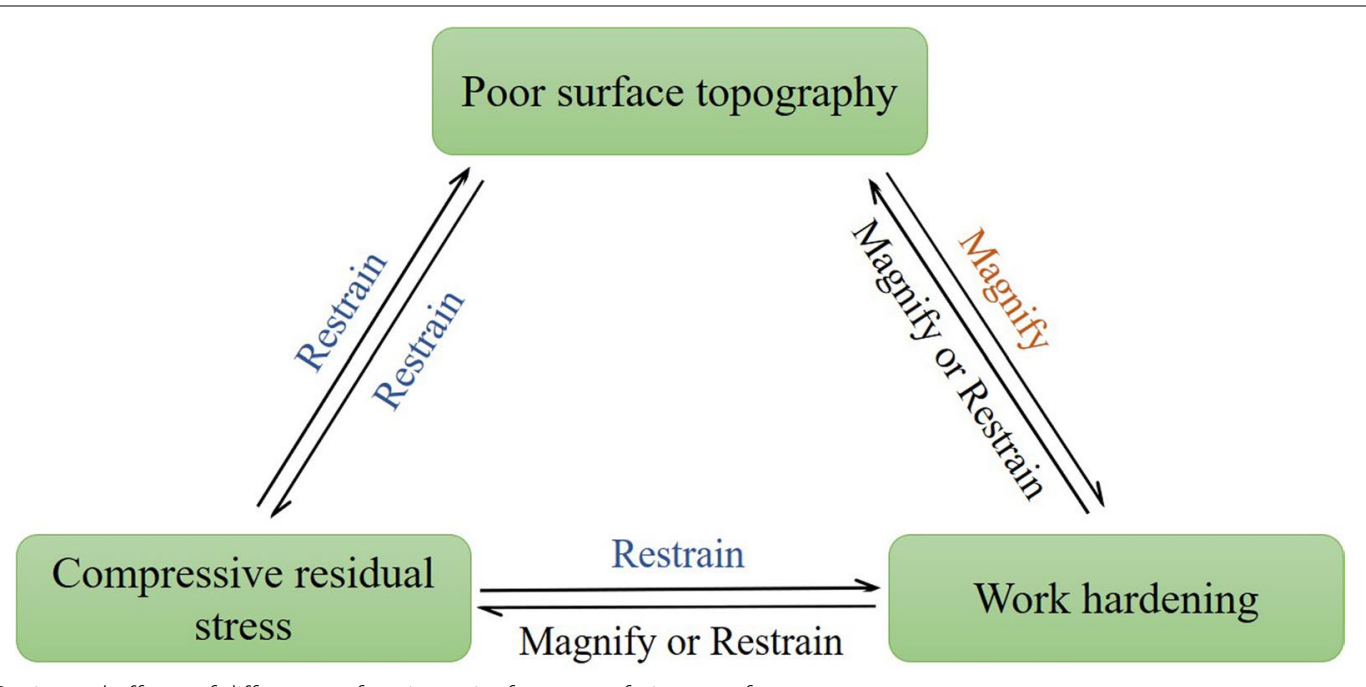

Figure 10 Reciprocal effects of different surface integrity factors on fatigue performance

stress can inhibit crack propagation $[8,49]$. Therefore, the effects of work hardening and compressive residual stress may restrain mutually.

The complicated reciprocal effects of different surface integrity factors on fatigue performance increased the difficulty of revealing the influence mechanism of surface integrity on fatigue performance and in establishing the accurate prediction model of fatigue limit. A better way or model to study and characterize the effect of surface integrity on fatigue performance is crucial.

\section{Conclusions}

This paper summarized the current state-of-the-art studies on the effects of machined surface integrity, including the surface topography, residual stress, work hardening, and metallurgical structure changes on workpiece fatigue performance. The reciprocal effects of these factors on material fatigue performance were also discussed. Based on the discussion above, the main conclusions were summarized as follows. The limitations in existing studies and the future directions in anti-fatigue manufacturing field were proposed.

(1) The fatigue performance of machined workpiece was determined comprehensively by the surface topography (including the surface roughness, local defects and inclusions), residual stress, work hardening, and metallurgical structure changes. However, the complicated reciprocal effects of these factors on fatigue performance and an effective prediction model of fatigue limit are crucial.

(2) The stress concentration factor $\left(K_{t}\right)$ was a useful indicator to describe the effect of surface topography on fatigue performance to some extent. However, the existing models and methods for calculating $K_{t}$ ignored the material properties and the critical value of defects and inclusions, which need to be improved further.

(3) Compressive residual stress is propitious to workpiece fatigue performance. However, the residual stress relaxation under the cycle loadings needs further studies to predict its effects more precisely.

(4) The effect of work hardening on fatigue performance was two-faced. The work hardening induced high yield strength could delay crack nucleation, but the increased brittleness could accelerate crack propagation. In addition, the effect of work hardening was closely related to the metallurgical structure changes. Finding the effective control mechanism and method of work hardening and metallurgical structure changes to enhance the fatigue performance of machined components is urgently needed.

(5) Complicated reciprocal effects were discussed among the surface integrity parameters. The effects of poor surface topography and compressive residual stress on fatigue performance inhibit each other. The reciprocal effect of poor surface topography and work hardening was two-faced (magnify or restrain each other). The compressive residual stress can restrain the effect of work hardening on fatigue performance, whereas the work hardening may magnify or restrain the effect of compressive residual stress.

\section{Acknowledgements}

Not applicable.

\section{Authors' contributions}

GL analyzed the effect of metallurgical structure changes and reciprocal effect of different factors on fatigue performance, and wrote the most part of the manuscript. CH guided the overall thoughts of the manuscript and analyzed 
the effect of surface topography on fatigue performance. BZ analyzed the effect of residual stress on fatigue performance. WW and SS analyzed the effect of work hardening on fatigue performance. All authors read and approved the final manuscript.

\section{Authors' Information}

Guoliang Liu, born in 1990, is currently an associate professor at School of Mechanical \& Automotive Engineering, Qingdao University of Technology, China. He received his PhD degree from Shandong University, China, in 2019. His research interests include high performance and green machining technology, micro texture design and laser processing technology.

Chuanzhen Huang, born in 1966, is currently a professor at School of Mechanical Engineering, Shandong University, China.

Bin Zhao, born in 1991, is currently a post-doctoral at Fraunhofer Institute for Mechanics of Materials IWM, Germany.

Wei Wang, born in 1988, is currently a lecturer at College of Mechanical and Electronic Engineering, China University of Petroleum (East China), China. Shufeng Sun, born in 1968, is currently a professor at School of Mechanical \& Automotive Engineering, Qingdao University of Technology, China.

\section{Funding}

Supported by National Natural Science Foundation of China (Grant No. 52005281), Major Program of Shandong Province Natural Science Foundation of China (Grant No. ZR2018ZA0401), and Applied Basic Research Projects for Qingdao Innovation Plan (Grant No. 18-2-2-67-jch).

\section{Competing Interests}

The authors declare no competing financial interests.

\section{Author Details}

${ }^{1}$ School of Mechanical \& Automotive Engineering, Qingdao University of Technology, Qingdao 266033, China. ${ }^{2}$ Center for Advanced Jet Engineering Technologies (CaJET), Key Laboratory of High-efficiency and Clean Mechanical Manufacture (Ministry of Education), National Experimental Teaching Demonstration Center for Mechanical Engineering (Shandong University), School of Mechanical Engineering, Shandong University, Jinan 250061, China. ${ }^{3}$ Fraunhofer Institute for Mechanics of Materials IWM, Wöhlerstraße 11, 79108 Freiburg, Germany. ${ }^{4}$ College of Mechanical and Electronic Engineering, China University of Petroleum (East China), Qingdao 266580, China.

\section{Received: 13 May 2020 Revised: 5 March 2021 Accepted: 27 October} 2021

Published online: 04 December 2021

\section{References}

[1] B A Cowles. High cycle fatigue in aircraft gas turbines-an industry perspective. International Journal of Fracture, 1996, 80(2):147-163.

[2] S Hasunuma, S Oki, K Motomatsu, et al. Fatigue life prediction of carbon steel with machined surface layer under low-cycle fatigue. International Journal of Fatigue, 2019, 123: 255-267.

[3] Y S Niu, P Zhao, X Li, et al. Influence of finish milling parameters on machined surface integrity and fatigue behavior of Ti1023 workpiece. The International Journal of Advanced Manufacturing Technology, 2017 91(1): 1297-1307.

[4] D Novovic, R C Dewes, D K Aspinwall, et al. The effect of machined topography and integrity on fatigue life. International Journal of Machine Tools \& Manufacture, 2004, 44(2-3): 125-134.

[5] G L Liu, C Z Huang, R Su, et al. 3D FEM simulation of the turning process of stainless steel 17-4PH with differently texturized cutting tools. International Journal of Mechanical Sciences, 2019, 155: 417-429.

[6] S Smith, S N Melkote, E Lara-Curzio, et al. Effect of surface integrity of hard turned AISI 52100 steel on fatigue performance. Materials Science and Engineering: A, 2007, 459(1-2): 337-346.

[7] F Hashimoto, Y B Guo, A W Warren. Surface integrity difference between hard turned and ground surfaces and its impact on fatigue life. CIRP Annals, 2006, 55(1): 81-84

[8] Y B Guo, A W Warren. The impact of surface integrity by hard turning vs. grinding on fatigue damage mechanisms in rolling contact. Surface \& Coatings Technology, 2008, 203(3): 291-299.
[9] Y B Guo, DW Yen. Hard turning versus grinding - The effect of processinduced residual stress on rolling contact. Wear, 2004, 256(3): 393-399.

[10] A M Abrāo, D K Aspinwall. The surface integrity of turned and ground hardened bearing steel. Wear, 1996, 196: 279-284.

[11] A R Sharman, D K Aspinwall, R C Dewes, et al. The effects of machined workpiece surface integrity on the fatigue life of $\gamma$-titanium aluminide. International Journal of Machine Tools \& Manufacture, 2001, 41(11): 1681-1685.

[12] S A Bentley, A L Mantle, D K Aspinwall. The effect of machining on the fatigue strength of a gamma titanium aluminide intermetallic alloy. Intermetallics, 1999, 7(8): 967-969.

[13] L Xun, C M Guan, P Zhao. Influences of milling and grinding on machined surface roughness and fatigue behavior of GH4169 superalloy workpieces. Chinese Journal of Aeronautics, 2017, 31 (6): 1399-1405.

[14] D Taylor, O M Clancy. The fatigue performance of machined surfaces. Fatigue \& Fracture of Engineering Materials \& Structures, 2010, 14(2-3): 329-336.

[15] D Novovic, D K Aspinwall, R C Dewes, et al. The effect of surface and subsurface condition on the fatigue life of ti-25v-15cr-2al-0.2c\%wt alloy. CIRP Annals Manufacturing Technology, 2016, 65(1): 523-528.

[16] F Ghanem, H Sidhom, C Braham, et al. Effect of near-surface residual stress and microstructure modification from machining on the fatigue endurance of a tool steel. Journal of Materials Engineering and Performance, 2002, 11(6): 631-639.

[17] TM Mower. Degradation of titanium 6Al-4V fatigue strength due to electrical discharge machining. International Journal of Fatigue, 2014, 64 84-96.

[18] M Lundberg, J Saarimaki, J Moverare, et al. Surface integrity and fatigue behaviour of electric discharged machined and milled austenitic stainless steel. Materials Characterization, 2017, 124: 215-222.

[19] L Wagner. Mechanical surface treatments on titanium, aluminum and magnesium alloys. Materials Science and Engineering: A, 1999, 263(2): 210-216.

[20] Z K Xu, J Dunleavey, M Antar, et al. The influence of shot peening on the fatigue response of Ti-6Al-4V surfaces subject to different machining processes. International Journal of Fatigue, 2018, 111: 196-207.

[21] D Yang, Z Q Liu, XXiao, et al. The effects of machining-induced surface topography on fatigue performance of titanium alloy Ti-6Al-4V. Procedia CIRP, 2018, 71: 27-30.

[22] XY Wang, C Z Huang, B Zou, et al. Experimental study of surface integrity and fatigue life in the face milling of Inconel 718 . Frontiers in Mechanical Engineering, 2018, 13(2): 243-250.

[23] W MHuang, J Zhao, JT Niu, et al. Comparison in surface integrity and fatigue performance for hardened steel ball-end milled with different milling speeds. Procedia CIRP, 2018, 71: 267-271.

[24] Y Choi. Effects of cutting speed on surface integrity and fatigue performance of hard machined surfaces. International Journal of Precision Engineering and Manufacturing, 2019, 20(1): 139-146.

[25] Y Choi. Influence of feed rate on surface integrity and fatigue performance of machined surfaces. International Journal of Fatigue, 2015, 78: 46-52.

[26] A Javidi, U Rieger, W Eichlseder. The effect of machining on the surface integrity and fatigue life. International Journal of Fatique, 2008, 30(10): 2050-2055.

[27] A Pramanik, M N Islam, I J Davies, et al. Contribution of machining to the fatigue behaviour of metal matrix composites (MMCs) of varying reinforcement size. International Journal of Fatigue, 2017, 102: 9-17.

[28] Y Choi. Influence of rake angle on surface integrity and fatigue performance of machined surfaces. International Journal of Fatigue, 2017, 94 81-88.

[29] H K Akyildiz, H Livatyali. Effects of machining parameters on fatigue behavior of machined threaded test specimens. Materials \& Design, 2010, 31(2): 1015-1022.

[30] J Holmberg, J C Berglund, A Wretland, et al. Evaluation of surface integrity after high energy machining with EDM, laser beam machining and abrasive water jet machining of alloy 718 . The International Journal of Advanced Manufacturing Technology, 2019, 100(5): 1575-1591.

[31] A Warhadpande, F Sadeghi. Effects of surface defects on rolling contact fatigue of heavily loaded lubricated contacts. Proceedings of the Institution of Mechanical Engineers, Part J: Journal of Engineering Tribology, 2010, 224(10): 1061-1077. 
[32] S Güngö, L Edwards. Effect of surface texture on the initiation and propagation of small fatigue cracks in a forged 6082 aluminium alloy. Materials Science and Engineering: A, 1993, 160(1): 17-24.

[33] M Taraf, E H Zahaf, O Oussouaddi, et al. Numerical analysis for predicting the rolling contact fatigue crack initiation in a railway wheel steel. Tribology International, 2010, 43(3): 585-593.

[34] A Fatemi, R Molaei, S Sharifimehr, et al. Torsional fatigue behavior of wrought and additive manufactured Ti-6Al-4V by powder bed fusion including surface finish effect. International Journal of Fatique, 2017, 99: 187-201.

[35] H Sasahara. The effect on fatigue life of residual stress and surface hardness resulting from different cutting conditions of $0.45 \% \mathrm{C}$ steel. International Journal of Machine Tools \& Manufacture, 2005, 45(2): 131-136.

[36] A Klumpp, S Maier, H Chen, et al. Influence of work-hardening on fatigue crack growth, effective threshold and crack opening behavior in the nickel-based superalloy Inconel 718. International Journal of Fatigue, 2018, 116: 257-267.

[37] H Sidhom, N Ben Moussa, B Ben Fathallah, et al. Effect of surface properties on the fatigue life of manufactured parts: Experimental analysis and multi-axial criteria. Advanced Materials Research, 2014, 996: 715-721.

[38] L Trsko, O Bokuvka, F Novy, et al. Effect of severe shot peening on ultra-high-cycle fatigue of a low-alloy steel. Materials \& Design, 2014, 57: 103-113.

[39] M Fernandes, M Torres, M Fonseca, et al. Investigation of residual stress, stress relaxation and work hardening effects induced by shot peening on the fatigue life of AA 6005-T6 aluminum alloy. Materials Research Express, 2020, 6: $1265 i 2$.

[40] M Nakajima, Y Uematsu, T Kakiuchi, et al. Effect of quantity of martensitic transformation on fatigue behavior in type 304 stainless steel. Procedia Engineering, 2011, 10(7): 299-304.

[41] E R D L Rio, A Navarro. Grain orientation and work hardening considerations on short fatigue crack modelling. Philosophical Magazine A, 1990, 61(3): 435-449.

[42] J Walker, D J Thomas, Y Gao. Effects of shot peening and pre-strain on the fatigue life of dual phase martensitic and bainitic steels. Journal of Manufacturing Processes, 2017, 26: 419-424.

[43] S Saberifar, A Mashreghi, M Mosalaeepur, et al. The interaction between non-metallic inclusions and surface roughness in fatigue failure and their influence on fatigue strength. Materials \& Design, 2012, 35: 720-724.

[44] B Vayssette, N Saintier, C Brugger, et al. Numerical modelling of surface roughness effect on the fatigue behavior of Ti-6Al-4V obtained by additive manufacturing. International Journal of Fatigue, 2019, 123: 180-195.

[45] N T Aboulkhair, I Maskery, C Tuck, et al. Improving the fatigue behaviour of a selectively laser melted aluminium alloy: Influence of heat treatment and surface quality. Materials \& Design, 2016, 104: 174-182.

[46] A Fatemi, R Molaei, S Sharifimehr, et al. Multiaxial fatigue behavior of wrought and additive manufactured Ti-6Al-4V including surface finish effect. International Journal of Fatigue, 2017, 100: 347-366.

[47] C Prakash, H K Kansal, B S Pabla, et al. Powder mixed electric discharge machining: an innovative surface modification technique to enhance fatigue performance and bioactivity of $\beta$-Ti implant for orthopedics application. Journal of Computing and Information Science in Engineering, 2016, 16(4): 041006

[48] S Bagehorn, J Wehr, H J Maier. Application of mechanical surface finishing processes for roughness reduction and fatigue improvement of additively manufactured Ti-6Al-4V parts. International Journal of Fatigue, 2017, 102: 135-142.

[49] LWagner, J K Gregory. Thermomechanical surface treatment of titanium alloys. Materials Science Forum, 1994, 163: 159-172.

[50] J Gunther, S Leuders, P Koppa, et al. On the effect of internal channels and surface roughness on the high-cycle fatigue performance of Ti-6Al-4V processed by SLM. Materials \& Design, 2018, 143: 1-11.

[51] JW Pegues, M D Roach, R S Williamson, et al. Surface roughness effects on the fatigue strength of additively manufactured Ti-6Al-4V. International Journal of Fatique, 2018, 116: 543-552.

[52] A Suarez, F Veiga, L N De Lacalle, et al. Effects of ultrasonics-assisted face milling on surface integrity and fatigue life of Ni-Alloy 718. Journal of Materials Engineering and Performance, 2016, 25(11): 5076-5086.
[53] CShao, H Cui, F Lu, et al. Quantitative relationship between weld defect characteristic and fatigue crack initiation life for high-cycle fatigue property. International Journal of Fatigue, 2019, 123: 238-247.

[54] W Koster. Effect of residual stress on fatigue of structural alloys. Practical Applications of Residual Stress Technology, Conference Proceedings, Indianapolis, Indiana, 1991: 1-9.

[55] A Pramanik, A K Basak. Fracture and fatigue life of Al-based MMCs machined at different conditions. Engineering Fracture Mechanics, 2018, 191: 33-45.

[56] S Beretta, S Romano. A comparison of fatigue strength sensitivity to defects for materials manufactured by AM or traditional processes. International Journal of Fatigue, 2017, 94: 178-191.

[57] D Arola, C L Williams. Estimating the fatigue stress concentration factor of machined surfaces. International Journal of Fatigue, 2002, 24(9): 923-930.

[58] A S Guilherme, G E Henriques, R A Zavanelli, et al. Surface roughness and fatigue performance of commercially pure titanium and Ti-6Al-4V alloy after different polishing protocols. Journal of Prosthetic Dentistry, 2005, 93(4): 378-385.

[59] N A Alang, N A Razak, A K Miskam. Effect of surface roughness on fatigue life of notched carbon steel. International Journal of Engineering \& Technology, 2011, 11(1): 160-163.

[60] M Suraratchai, J Limido, C Mabru, et al. Modelling the influence of machined surface roughness on the fatigue life of aluminium alloy. International Journal of Fatigue, 2008, 30(12): 2119-2126.

[61] M R Bayoumi, A K Abdellatif. Effect of surface finish on fatigue strength. Engineering Fracture Mechanics, 1995, 51(5): 861-870.

[62] F Abroug, E Pessard, G Germain, et al. A probabilistic approach to study the effect of machined surface states on HCF behavior of a AA7050 alloy. International Journal of Fatigue, 2018, 116: 473-489.

[63] B Griffiths. Manufacturing surface technology: Surface integrity and functional performance. Elsevier, 2001

[64] E Siebel. Influence of surface roughness on the fatigue strength of steels and non-ferrous alloys. Engineers Digest, 1957, 18: 109-112.

[65] G R Leverant, B S Langer, A Yuen, et al. Surface residual stresses, surface topography and the fatigue behavior of Ti-6Al-4V. Metallurgical and Materials Transactions A-physical Metallurgy and Materials Science, 1979, 10(2): 251-257.

[66] F Abroug, E Pessard, G Germain, et al. HCF of AA7050 alloy containing surface defects: Study of the statistical size effect. International Journal of Fatigue, 2018, 110: 81-94.

[67] A R Balachandramurthi, J Moverare, N Dixit, et al. Influence of defects and as-built surface roughness on fatigue properties of additively manufactured Alloy 718. Materials Science and Engineering: A, 2018, 735: 463-474

[68] A L Mantle, D K Aspinwall. Surface integrity and fatigue life of turned gamma titanium aluminide. Journal of Materials Processing Technology, 1997, 72(3): 413-420.

[69] J C Newman, E P Phillips, M H Swain. Fatigue-life prediction methodology using small-crack theory. International Journal of Fatigue, 1999, 21: 109-119.

[70] H L Deng, Q C Liu, H Liu, et al. Long-life fatigue of carburized 12cr2ni alloy steel: Evaluation of failure characteristic and prediction of fatigue strength. Metals, 2018, 8(12): 1006.

[71] B Skallerud, S K Ås, N S Ottosen. A gradient-based multiaxial criterion for fatigue crack initiation prediction in components with surface roughness. International Journal of Fatigue, 2018, 117: 384-395.

[72] H Neuber. Theory of stress concentration for shear-strained prismatical bodies with arbitrary nonlinear stress-strain law. Journal of Applied Mechanics, 1961, 28(4): 544-550.

[73] D Arola, M Ramulu. An examination of the effects from surface texture on the strength of fiber reinforced plastics. Journal of Composite Materials, 1999, 33(2): 102-123.

[74] S K As, B Skallerud, B W Tveiten, et al. Fatique life prediction of machined components using finite element analysis of surface topography. International Journal of Fatique, 2005, 27(10): 1590-1596.

[75] Y B Gao, X B Li, Q X Yang, et al. Influence of surface integrity on fatigue strength of 40CrNi2Si2MoVA steel. Materials Letters, 2007, 61 (2): 466-469. 
[76] G L Liu, C Z Huang, B Zou, et al. Surface integrity and fatigue performance of $17-4 \mathrm{PH}$ stainless steel after cutting operations. Surface \& Coatings Technology, 2016, 307: 182-189.

[77] J Seo, B C Goo, J Choi, et al. Effects of metal removal and residual stress on the contact fatique life of railway wheels. International Journal of Fatigue, 2008, 30(10): 2021-2029.

[78] Z Chen, J Moverare, R L Peng, et al. Surface integrity and fatigue performance of inconel 718 in wire electrical discharge machining. Procedia CIRP, 2016, 45: 307-310.

[79] M Gerstenmeyer, F Zanger, V Schulze. Influence of complementary machining on fatigue strength of AISI 4140. CIRP Annals, 2018, 67(1): 583-586.

[80] F Ghanem, N B Fredj, H Sidhom, et al. Effects of finishing processes on the fatigue life improvements of electro-machined surfaces of tool steel. The International Journal of Advanced Manufacturing Technology, 2011, 52(5): 583-595.

[81] B R Sridhar, K Ramachandra, K A Padmanabhan. Effect of shot peening on the fatigue and fracture behaviour of two titanium alloys. Journal of Materials Science, 1996, 31(22): 5953-5960.

[82] T Klotz, D Delberque, P Bocher, et al. Surface characteristics and fatigue behavior of shot peened Inconel 718. International Journal of Fatigue, 2018, 110: 10-21.

[83] R Aviles, J Albizuri, A Rodriguez, et al. Influence of low-plasticity ball burnishing on the high-cycle fatigue strength of medium carbon AISI 1045 steel. International Journal of Fatigue, 2013, 55: 230-244.

[84] C Yao, L Ma, Y Du et al. Surface integrity and fatigue behavior in shotpeening for high-speed milled 7055 aluminum alloy. Proceedings of the Institution of Mechanical Engineers, Part B: Journal of Engineering Manufacture, 2017, 231(2): 243-256.

[85] B Gerin, E Pessard, F Morel, et al. Influence of surface integrity on the fatigue behaviour of a hot-forged and shot-peened C70 steel component. Materials Science and Engineering: A, 2017, 686: 121-133.

[86] G L Liu, C Z Huang, B Zou, et al. Feasibility study of taking high-speed dry milling as the final manufacturing process by the standard of service performance. The International Journal of Advanced Manufacturing Technology, 2018, 95(5): 2897-2906.

[87] S O A El-Helieby, G W Rowe. Influences of surface roughness and residual stress on fatique life of ground steel components. Metals Technology, 1980, 7(1): 221-225.

[88] Y Liu, J Liu and X Shao. Study on the residual stress fields, surface quality, and fatigue performance of cold expansion hole. Materials and Manufacturing Processes, 2011, 26(2): 294-303.

[89] C J Lammi, D A Lados. Effects of residual stresses on fatigue crack growth behavior of structural materials: Analytical corrections. International Journal of Fatigue, 2011, 33(7): 858-867.

[90] Y Ochi, K Masaki, T Matsumura, et al. Effect of shot-peening treatment on high cycle fatigue property of ductile cast iron. International Journal of Fatigue, 2001, 23(5): 441-448.

[91] C Yao, D Wu, L Ma, et al. Surface integrity evolution and fatigue evaluation after milling mode, shot-peening and polishing mode for TB6 titanium alloy. Applied Surface Science, 2016, 387: 1257-1264.

[92] M Liu, JTakagi, A Tsukuda. Effect of tool nose radius and tool wear on residual stress distribution in hard turning of bearing steel. Journal of Materials Processing Technology, 2004, 150(3): 234-241.

[93] G L Liu, C Z Huang, B Zou, et al. The modification of corrosion resistance of 17-4PH stainless steel by cutting process. Journal of Manufacturing Processes, 2020, 49: 447-455

[94] Y Hua, Z Q Liu, B Wang, et al. Surface modification through combination of finish turning with low plasticity burnishing and its effect on fatique performance for Inconel 718. Surface \& Coatings Technology, 2019, 375: 508-517.

[95] D W Schwach, Y B Guo. A fundamental study on the impact of surface integrity by hard turning on rolling contact fatigue. International Journal of Fatigue, 2006, 28(12): 1838-1844.

[96] A Drechsler, T Dorr, L Wagner. Mechanical surface treatments on Ti-10V-2Fe-3Al for improved fatigue resistance. Materials Science and Engineering: A, 1998, 243(1): 217-220.

[97] A M Hassan, A Momani. Further improvements in some properties of shot peened components using the burnishing process. International Journal of Machine Tools \& Manufacture, 2000, 40(12): 1775-1786.
[98] M Benedetti, V Fontanari, P Scardi, et al. Reverse bending fatigue of shot peened 7075-T651 aluminium alloy: The role of residual stress relaxation. International Journal of Fatigue, 2009, 31(8): 1225-1236.

[99] N Hempel, J R Bunn, T Nitschkepagel, et al. Study on the residual stress relaxation in girth-welded steel pipes under bending load using diffraction methods. Materials Science and Engineering: A, 2017, 688: 289-300.

[100] G L Liu, C Z Huang, HT Zhu, et al. The modified surface properties and fatigue life of Incoloy A286 face-milled at different cutting parameters. Materials Science and Engineering: A, 2017, 704(704): 1-9.

[101] D Yang, Z Q Liu. Surface integrity generated with peripheral milling and the effect on low-cycle fatigue performance of aeronautic titanium alloy Ti-6Al-4V. The Aeronautical Journal, 2018, 122(1248): 316-332.

[102] AT Özdemir, L Edwards. Relaxation of residual stresses at cold-worked fastener holes due to fatigue loading. Fatigue \& Fracture of Engineering Materials \& Structures, 1997, 20(10): 1443-1451.

[103] K Dalaei, B Karlsson, L E Svensson. Stability of shot peening induced residual stresses and their influence on fatigue lifetime. Materials Science and Engineering: A, 2011, 528(3): 1008-1015.

[104] W Z Zhuang, G R Halford. Investigation of residual stress relaxation under cyclic load. International Journal of Fatigue, 2001, 23: 31-37.

[105] M A Torres, H J Voorwald. An evaluation of shot peening, residual stress and stress relaxation on the fatigue life of AISI 4340 steel. International Journal of Fatigue, 2002, 24(8): 877-886

[106] S S Crețu, N G Popinceanu. The influence of residual stresses induced by plastic deformation on rolling contact fatigue. Wear, 1985, 105(2): 153-170.

[107] L Yan, W Yang, $H$ Jin, et al. Analytical modelling of microstructure changes in the machining of 304 stainless steel. The International Journal of Advanced Manufacturing Technology, 2012, 58(1): 45-55.

[108] X P Ren, Z Q Liu. Influence of cutting parameters on work hardening behavior of surface layer during turning superalloy Inconel 718. The International Journal of Advanced Manufacturing Technology, 2016, 86(58): 2319-2327.

[109] C P Jones, W R Tyfour, J H Beynon, et al. The effect of strain hardening on shakedown limits of a pearlitic rail steel. Proceedings of the Institution of Mechanical Engineers Part F Journal of Rail \& Rapid Transit, 1997, 211(2): 131-140.

[110] Y Murakami. Metal fatique: effects of small defects and nonmetallic inclusions. Academic Press, 2019.

[111] SI Nishida, C Zhou, N Hattori, et al. Fatique strength improvement of notched structural steels with work hardening. Materials Science \& Engineering: A, 2007, 468: 176-183.

[112] SM Lyalikov. Effect of surface plastic deformation on the inelastic characteristics and fatigue limit of steels 20 and 14kh17n2 with cyclic torsion. Strength of Materials, 1989, 21(5): 687-690.

[113] T Fukui, K Matuda, T Fujita, et al. Influence of work hardening on the rolling contact fatigue strength of the stainless steel (sus 304, sus 405). Journal of the Society of Materials Science Japan, 1985, 33(4): 1033-1038.

[114] F P Inés, M Guagliano. About the role of residual stresses and surface work hardening on fatigue $\Delta \mathrm{kth}$ of a nitrided and shot peened lowalloy steel. Surface \& Coatings Technology, 2008, 202(13): 3072-3080.

[115] PT Iswanto, S I Nishida, N Hattori, et al. Effect of roller-working on fatique strength improvement of notched structural stainless steel. Key Engineering Materials, 2006, 306-308(Pt1): 151-156.

[116] A Lanzutti, M Pujatti, M Magnan, et al. Uniaxial fatigue properties of closed die hot forged 42CrMo4 steel: Effect of flash and mechanical surface treatments. Materials \& Design, 2017, 132: 324-336.

[117] X Zhao, G Xue, Y Liu. Gradient crystalline structure induced by ultrasonic impacting and rolling and its effect on fatigue behavior of tc 11 titanium alloy. Results in Physics, 2017, 7: 1845-1851.

[118] M Calcagnotto, D Ponge, D Raabe. Effect of grain refinement to $1 \mu \mathrm{m}$ on strength and toughness of dual-phase steels. Materials Science and Engineering: A, 2010, 527(29-30): 7832-7840.

[119] H Somekawa, T Mukai. Effect of grain refinement on fracture toughness in extruded pure magnesium. Scripta Materialia, 2005, 53(9): 1059-1064.

[120] A Cox, S Herbert, J P Villainchastre, et al. The effect of machining and induced surface deformation on the fatigue performance of a high strength metastable $\beta$ titanium alloy. International Journal of Fatigue, 2019, 124: 26-33.

[121] Q Chen, X Leng, E Shao. Influence of microstructure and residual stress on the stages of case crushing. Wear, 1988, 122(1): 45-55. 
[122] JW Morris, Z Guo, C R Krenn, et al. The limits of strength and toughness in steel. ISIJ International, 2001, 41(6): 599-611.

[123] Y Uematsu, T Kakiuchi, M Akita, et al. Effect of strain-induced martensitic transformation on high cycle fatigue behavior in cyclically-prestrained type 304. Journal of the Society of Materials Science Japan, 2013, 62(12): 744-749.

[124] K Genel, M Demirkol, M Capa. Effect of ion nitriding on fatique behaviour of AISI 4140 steel. Materials Science and Engineering: A, 2000, 279(1): 207-216.
[125] Y B Guo, DW Schwach. An experimental investigation of white layer on rolling contact fatigue using acoustic emission technique. International Journal of Fatique, 2005, 27(9): 1051-1061.

[126] E A Shur, N Y Bychkova, S M Trushevsky. Physical metallurgy aspects of rolling contact fatigue of rail steels. Wear, 2005, 258(7): 1165-1171.

[127] C F Yao, L Tan, J Ren, et al. Surface integrity and fatigue behavior for high-speed milling Ti-10V-2Fe-3Al titanium alloy. Journal of Failure Analysis and Prevention, 2014, 14(1): 102-112.

\section{Submit your manuscript to a SpringerOpen ${ }^{\circ}$ journal and benefit from:}

- Convenient online submission

- Rigorous peer review

- Open access: articles freely available online

- High visibility within the field

- Retaining the copyright to your article

Submit your next manuscript at $\boldsymbol{\nabla}$ springeropen.com 